\title{
Chemokines and Chemokine Receptors: New Targets for Cancer Immunotherapy
}

\author{
Valeria Mollica Poeta ${ }^{1,2}$, Matteo Massara ${ }^{1}$, Arianna Capucetti ${ }^{1,2}$ and Raffaella Bonecchi ${ }^{1,2 *}$ \\ ${ }^{1}$ Humanitas Clinical and Research Center, IRCCS, Rozzano, Italy, ${ }^{2}$ Department of Biomedical Sciences, Humanitas \\ University, Pieve Emanuele, Italy
}

OPEN ACCESS

Edited by:

Giovanni Bernardini,

Sapienza University of Rome, Italy

Reviewed by:

Connie Duong

Institut Gustave Roussy, France

Flavia Trettel,

Sapienza University of Rome, Italy

${ }^{*}$ Correspondence:

Raffaella Bonecchi

raffaella.bonecchi@hunimed.eu

Specialty section:

This article was submitted to Cytokines and Soluble Mediators in Immunity,

a section of the journa

Frontiers in Immunology

Received: 21 November 2018

Accepted: 14 February 2019

Published: 06 March 2019

Citation:

Mollica Poeta V, Massara M, Capucetti A and Bonecchi R (2019)

Chemokines and Chemokine Receptors: New Targets for Cancer Immunotherapy.

Front. Immunol. 10:379. doi: 10.3389/fimmu.2019.00379
Immunotherapy is a clinically validated treatment for many cancers to boost the immune system against tumor growth and dissemination. Several strategies are used to harness immune cells: monoclonal antibodies against tumor antigens, immune checkpoint inhibitors, vaccination, adoptive cell therapies (e.g., CAR-T cells) and cytokine administration. In the last decades, it is emerging that the chemokine system represents a potential target for immunotherapy. Chemokines, a large family of cytokines with chemotactic activity, and their cognate receptors are expressed by both cancer and stromal cells. Their altered expression in malignancies dictates leukocyte recruitment and activation, angiogenesis, cancer cell proliferation, and metastasis in all the stages of the disease. Here, we review first attempts to inhibit the chemokine system in cancer as a monotherapy or in combination with canonical or immuno-mediated therapies. We also provide recent findings about the role in cancer of atypical chemokine receptors that could become future targets for immunotherapy.

Keywords: immunotherapy, cancer related inflammation, atypical chemokine receptor, chemokine receptor, chemokine

\section{ROLE OF CHEMOKINES IN TUMORS}

Inflammation is an essential component of the tumor microenvironment and one of the hallmarks of cancer $(1,2)$. Chemokines, are a family of small, secreted, and structurally related cytokines with a crucial role in inflammation and immunity (3). They are also key mediators of cancer related inflammation being present at tumor site for pre-existing chronic inflammatory conditions but also being target of oncogenic pathways (4). Initially identified with a prominent role in determining the composition of tumor stroma, they were found able to directly affect cancer cell proliferation and metastasis $(5,6)$.

\section{Leukocyte Recruitment}

The proper movement of immune cells is orchestrated by the spatial and temporal expression of chemokines. Inflammatory CC (CCL2, CCL3, CCL5) and CXC (CXCL1, CXCL2, CXCL5, CXCL6, and CXCL8) chemokines recruit at the tumor site CCR2 ${ }^{+}$monocytes and CXCR2 ${ }^{+}$ neutrophils that differentiate into tumor associated macrophages (TAMs) and tumor associated neutrophils (TANs), exerting pro- or anti-tumoral role (7-10). Some chemokines present at tumor site can modify leukocyte activation, for instance CXCL16 acting on CXCR6 induces macrophage polarization toward a pro-tumoral phenotype in solid tumors $(11,12)$. CXCL9 and CXCL10 are strongly associated with Th1 immune response by recruiting NK cells, CD4 ${ }^{+}$Th1 and $\mathrm{CD} 8^{+}$ cytotoxic lymphocytes, which can elicit antitumoral responses $(13,14)$. Moreover, potent attractant of dendritic cells (DC) are CCL20, CCL5, and CXCL12 (15); CCL21 and CCL19 recruit CCR7 ${ }^{+}$DC 
but also regulatory $\mathrm{T}$ cells $\left(\mathrm{T}_{\text {regs }}\right)(16,17)$. CCL17 and CCL22 acting on CCR4 can directly recruit $\mathrm{T}_{\text {regs }}$ and $\mathrm{Th} 2$ lymphocytes, that promote tumor growth and proliferation (18).

\section{Angiogenesis}

Both CC and CXC chemokines play a critical role in tumor angiogenesis, essential for tumor growth and metastatic spreading $(19,20)$. CXC chemokines, based on the presence of glutamic-leucine-arginine (ELR) motif at the N-terminal, can be divided in $\mathrm{ELR}^{+}$chemokines with angiogenic and $\mathrm{ELR}^{-}$ chemokines with angiostatic effects. CCL2, CCL11, CCL16, CCL18, and CXCL8 promote tumor angiogenesis and endothelial cell survival (21, 22). Moreover, CXCL16 interacting with CXCR6, acts as a potent angiogenic mediator (23). CXCL12 and CCL2 can promote angiogenesis and inhibit apoptosis of endothelial cells by directly binding their receptor (CXCR4 and CCR2, respectively) expressed on tumor vessels or indirectly promoting the recruitment of leukocytes $(24,25)$. On the contrary, chemokines, such as CCL21 and ELR ${ }^{-}$chemokines (CXCL4, CXCL9, CXCL10, and CXCL11) inhibit angiogenesis and endothelial cell proliferation (26).

\section{Tumor Growth and Proliferation}

Chemokines produced by tumor itself, cancer-associated fibroblasts and infiltrating leukocytes $(27,28)$, through the binding of chemokine receptors expressed by tumor cells, directly promote cancer cell proliferation activating different signaling pathways, such as PI3K/AKT/NF-кB and MAPK/ERK pathway (29-31). Additionally, they can promote tumor cell survival by preventing their apoptosis and regulating the balance between pro- and anti-apoptotic molecules (e.g., downregulation of Bcl-2 expression or inhibition of caspase-3 and caspase- 9 activation) $(32,33)$.

\section{Metastasis}

Chemokine receptors expressed by cancer cells promote their migration to metastatic sites (34). Chemokines and chemokine receptors involved in this phenomenon are several: CCR7 mediates the migration of tumor cells to lymph nodes where their ligands, CCL19 and CCL21, are produced (34, 35). The CCR10/CCL27 axis facilitates the adhesion and survival of melanoma cells during metastatic spreading (36). CCL28 promotes breast cancer growth and metastasis spreading through MAPK/ERK pathway (37). Finally the chemokine receptor CXCR5 and its ligand CXCL13 support bone metastases in prostate cancer (38). However, the main player of this process is the CXCL12/CXCR4 axis. In several tumors, CXCR4 expression endows cancer cells with the ability to migrate and metastasize into organs secreting high levels of CXCL12 $(6,39)$.

\section{CHEMOKINES IN CANCER THERAPY}

Targeting the immune system represents a concrete approach against cancer (40-42). Starting from Coley's toxin development in 1893, many strategies have been set to enhance the antitumor activity of leukocytes $(42,43)$. Given that chemokines and their receptors have been found involved in several aspects of cancer biology, their possible targeting was evaluated in many preclinical studies and clinical trials (Table 1 and Figure 1). Actually, a monoclonal antibody (anti-CCR4 mAb, Mogamulizumab) and a chemokine receptor inhibitor (CXCR4 antagonist AMD3100) are already in the clinical practice for hematological malignancies (see below).

\section{CCR1}

Inhibition of CCR1 reduces cancer growth and metastatization mainly by targeting myeloid cells. In mouse models of Multiple Myeloma (MM) the CCR1 antagonist CCX721 reduced tumor growth and osteolysis targeting osteoclasts and their precursors $(44,45)$. The same effect was also given by blocking the CCR1 ligand CCL3 that is highly produced by MM cells (95). In a murine model of colon cancer liver metastasis, the CCR1 antagonist BL5923 inhibited metastasis by limiting the recruitment of immature myeloid cells (46). The CCR1 receptor antagonist CCX9588 was recently used in combination with anti-PD-L1 in a murine model of breast cancer showing a synergistic antitumoral effect by reducing the myeloid infiltrate (47). Due to the fact that CCR1 antagonists did not show adverse effects when used in autoimmune disease patients (96), they are ideal candidates to modulate the myeloid infiltrate in combination treatments.

\section{CCR2 and CCL2}

Interference with the CCL2/CCR2 axis exerts antitumoral activity in many cancers for the reduced recruitment of monocytes with pro-tumorigenic and pro-metastatic activities.

Many data are available in the context of pancreatic tumors. In a preclinical model, the oral CCR2 inhibitor PF-04136309 reduced the number of TAMs and exerted a modest effect on tumor growth when used alone, while it acted synergistically with the chemotherapeutic drug Gemcitabine (GEM) (48). Encouraging results of a Phase Ib/II trial with pancreatic cancer patients, in which PF-04136309 is used in combination with nab-Paclitaxel [(PTX), a nanoparticle albumin-bound formulation of PTX able to induce TAM activation toward an M1 like phenotype] (97), and GEM, were recently published (NCT02732938) (49). The same inhibitor was used in another clinical trial (NCT01413022) performed on borderline resectable or locally advanced pancreatic ductal adenocarcinoma patients in combination with the standard chemotherapy FOLFIRINOX (FX). Preliminary results demonstrated that the combination therapy increased the percentage of objective responses (51). Another CCR2 inhibitor, CCX872, is really promising in the context of pancreatic tumors. In a preclinical setting, it improved the efficacy of the anti-PD-1 treatment (50) and positive results were also obtained in a clinical trial (NCT02345408) when used in combination with FX (53). In murine models of hepatocellular carcinoma (HCC), CCR2 targeting with the antagonists RDC018 or 747 in combination with Sorafenib, reduced tumor growth and metastasis with a corresponding decrease in macrophage infiltration $(52,54)$. In prostate and breast cancer, CCR2 was found expressed by tumor cells and to promote cancer growth and migration (98, 99). However, targeting CCL2 with the humanized monoclonal 
TABLE 1 | Chemokine and chemokine receptor inhibitors in preclinical models and clinical trials.

\begin{tabular}{|c|c|c|c|c|c|c|}
\hline Target & \multicolumn{3}{|c|}{ Preclinical models } & \multicolumn{3}{|c|}{ Clinical trials } \\
\hline & BL5923 & $\begin{array}{l}\text { Colon cancer liver } \\
\text { metastasis }\end{array}$ & (46) & & & \\
\hline & CCX9588 + anti-PD-L1 & Breast cancer & $(47)$ & & & \\
\hline & CCX872 + anti-PD-1 & Pancreatic cancer & (50) & PF-04136309 + FX & $\begin{array}{l}\text { Pancreatic ductal } \\
\text { adenocarcinoma }\end{array}$ & NCT01413022; (51) \\
\hline & RDC018 & Hepatocellular carcinoma & (52) & $\mathrm{CCX} 872+\mathrm{FX}$ & Pancreatic cancer & NCT02345408; (53) \\
\hline & $747+$ Sorafenib & Hepatocellular carcinoma & (54) & & & \\
\hline & iCCR2 & Ovarian cancer & (55) & & & \\
\hline \multirow{2}{*}{ CCR4 } & Affi 5 & Renal tumor & (61) & & ATL & (60) \\
\hline & AF399/420/1802 & $\begin{array}{l}\text { Melanoma, lung tumor and } \\
\text { CRC }\end{array}$ & (62) & Mogamulizumab & CTL & NCT01728805; (63) \\
\hline CCR5 & Maraviroc & $\mathrm{CRC}$ & (64) & $\begin{array}{l}\text { Maraviroc + } \\
\text { chemotherapy }\end{array}$ & $\mathrm{CRC}$ & NCT01736813; (64) \\
\hline \multirow[t]{2}{*}{ CCR7 } & siRNA & $\begin{array}{l}\text { Metastatic CRC and } \\
\text { prostate cancer }\end{array}$ & $(65,66)$ & & & \\
\hline & MSM R707 & Metastatic T- ALL & (67) & & & \\
\hline \multirow[t]{3}{*}{ CXCR2 } & Cxcr2 $2^{-1-}+$ PTX & Breast cancer & (68) & AZD5069 & Pancreatic cancer & NCT02583477 \\
\hline & Navarixin + anti-MEK & Melanoma & (69) & Reparixin + PTX & Breast cancer & NCT02370238; (70) \\
\hline & SB225002 + Sorafenib & Ovarian cancer & (71) & & & \\
\hline \multirow{7}{*}{ CXCR4 } & BKT140 + Rituximab & $\mathrm{NHL}$ & (82) & BMS-936564 & AML & NCT01120457; (83) \\
\hline & AMD3465 & GBM and Medulloblastoma & (84) & PF-06747143 & $\begin{array}{l}\text { Hematologic } \\
\text { malignancies }\end{array}$ & NCT02954653 \\
\hline & POL5551 + anti-VEGF & GBM & $(85,86)$ & USL311 + Lomustine & Solid tumors and GBM & NCT02765165 \\
\hline & AMD3100 & Ovarian cancer & (87) & Balixafortide + Eribulin & $\begin{array}{l}\text { HER2 }{ }^{-} \text {metastatic } \\
\text { breast cancer }\end{array}$ & NCT01837095; (88) \\
\hline & AMD3100 + anti-PD-L1 & Pancreatic cancer & (89) & AMD3100 & Recurrent GBM & NCl2012-00149; \\
\hline & AMD3100 + VIC-008 & Mesothelioma & (90) & & & NCl2013-02012 \\
\hline & $\begin{array}{l}\text { PRX177561+Bevacizumab+ } \\
\text { Sunitinib }\end{array}$ & GBM & (91) & & & \\
\hline ACKR2 & Ackr2 -/- & $\begin{array}{l}\text { Metastatic breast cancer } \\
\text { and melanoma }\end{array}$ & $(92,93)$ & & & \\
\hline ACKR3 & X7Ab + Temozolomide & GBM & (94) & & & \\
\hline
\end{tabular}

CCL2 neutralizing antibody CNTO 888 in a phase I trial (NCT00537368) in solid tumors and in a phase II trial (NCT00992186) in metastatic prostate cancer, was unsuccessful due to ineffectiveness of CNTO 888 in reducing CCL2 serum level $(57,58)$. More recent preclinical data indicated that in breast cancer models inhibition of CCL2 improved the response to radiotherapy (100) and was effective in preventing metastasis (56), but its discontinuation caused a rebound in 


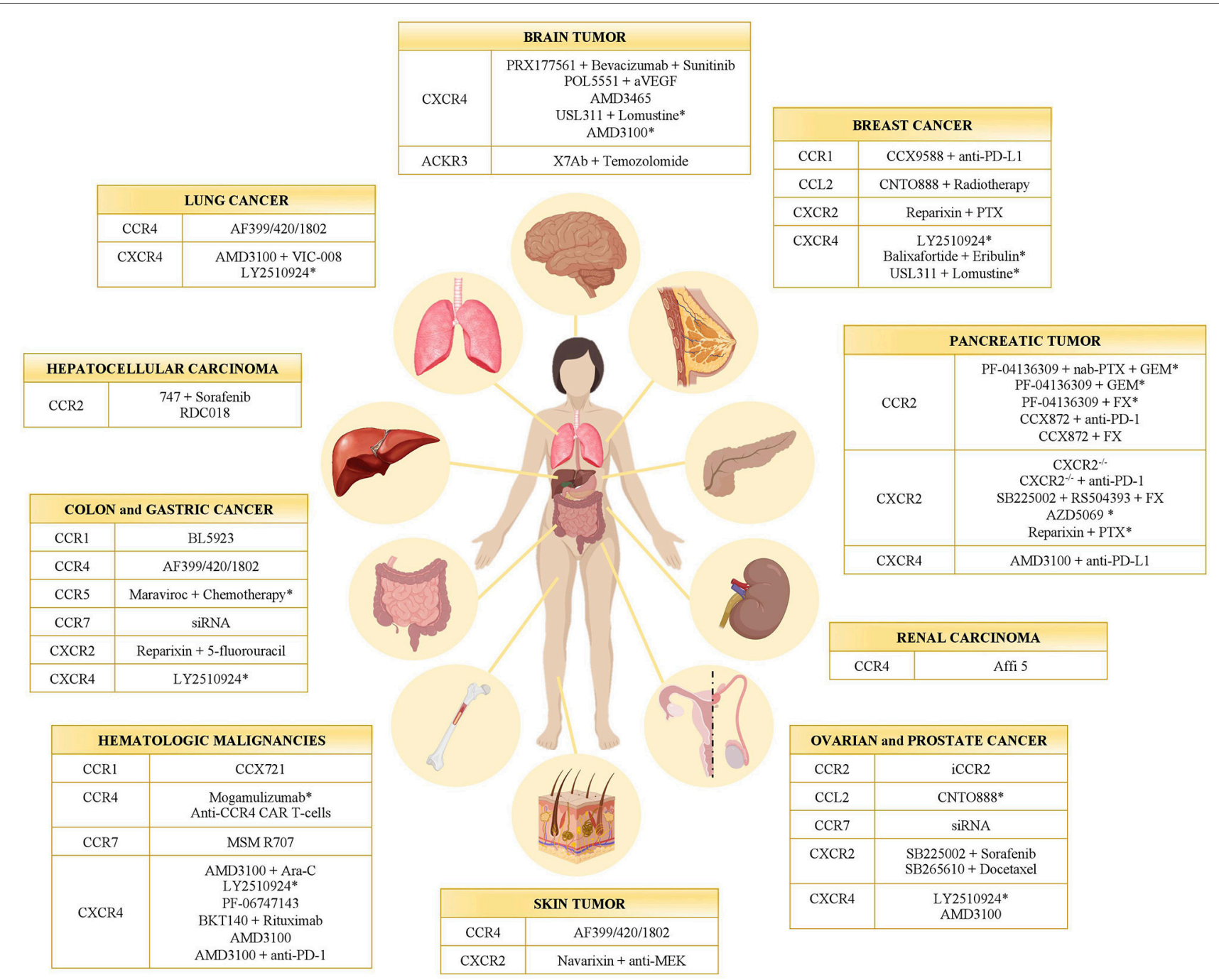

FIGURE 1 | Chemokine receptor inhibitors in cancer. Inhibitors of CC- and CXC-chemokine receptors tested in different tumor types in preclinical models and clinical trials (*). GEM, Gemcitabine; PTX, Paclitaxel; FX, FOLFIRINOX.

the number of circulating monocytes increasing metastatic spreading. Finally, in ovarian cancer, a CCR2 inhibitor enhanced peptide vaccination (55). All these data suggest that targeting the CCL2-CCR2 axis could be effective especially in combination therapies but attention has to be given to fluctuations in the number of circulating monocytes that can produce controversial effects (56).

\section{CCR4}

CCR4 is overexpressed in many hematologic malignancies such as Adult T-cell leukemia (ATL) and Cutaneous Tcell lymphoma (CTL). The human anti-CCR4 antibody Mogamulizumab eliminates tumor cells via antibody-dependent cellular cytotoxicity (ADCC) and is actually in use in Japan for the treatment of relapsed/refractory ATL (60). It is also considered the best therapy for previously treated CTL patients according to an international phase III trial (63). In addition, in preclinical studies, CAR-T cells generated against CCR4, were found effective in the treatment of a wide spectrum of $\mathrm{T}$ cell malignancies (59).

CCR4 is also considered a promising target for solid tumors for its activity in modulating leukocyte infiltrate, in particular for depleting $\mathrm{T}_{\text {regs. }}$ In a preclinical model of renal cancer, Affi 5, a CCR4 blocking $\mathrm{mAb}$, reduced tumor growth affecting the phenotype of myeloid cells and increasing the number of infiltrating NK cells (61). CCR4 is now considered a target for renal carcinoma patients (101). However, there are major concerns about the safety of the use of mAbs against CCR4 especially in patients previously subjected to allogenic bone marrow (BM) transplant. Anti-CCR4 mAbs are also depleting $\mathrm{T}_{\text {regs }}$ for few months, increasing the risk of graft-vs-host disease (102). For this reason, small molecule antagonists of CCR4 with less harmful side effects are in development and one of them, AF399/420/1802, considerably improved the efficacy of cancer vaccines in different preclinical tumor models (melanoma, lung, and colon cancer) by preventing $\mathrm{T}_{\text {regs }}$ induction (62). 


\section{CCR5}

The role of CCR5 in cancer remains still controversial; depending on the cell type on which it is expressed it can have a proor anti-tumoral role. When expressed by tumor cells it drives their growth and metastatization, while when expressed by $\mathrm{T}$ cells potentiates anti-tumoral responses (103). For instance in breast cancer, a dual role of the receptor has been reported in promoting antitumor immune responses, but being also associated with cancer progression and metastasis (104). More recent data indicate that CCR5 induces the mobilization of myeloid cells with pro-tumoral activity (105) and results obtained with preclinical and clinical models of colorectal cancer (CRC) indicate that targeting CCR5 with the negative allosteric inhibitor Maraviroc promoted the polarization of macrophages toward an antitumoral state. Very interestingly, objective partial response was reported in three out of five patients who received a combination of Maraviroc (NCT01736813) and chemotherapy (64). These data suggest that targeting CCR5 could have a major antitumoral effect on tumors that are CCR5 positive and have a prevalent myeloid infiltrate with immunosuppressive activity, while in other tumors CCR5 activity on T cells needs to be preserved for the correct development of the immune response.

\section{CCR7}

The therapeutic application of CCR7 inhibitors is also extremely promising. CCR7 is overexpressed by many tumors driving both tumor growth and metastatization. By the use of siRNA technology, CCR7 inhibition resulted in decreased number of metastasis in a model of colon carcinoma (65) and inhibited the growth of prostate cancer (66). Moreover, reduction of CCR7 expression in breast cancer inhibited metastasis (106) and single-chain antibodies blocking CCR7 (MSM R707) were found able to inhibit brain metastasis of T-cell acute lymphoblastic leukemia (107).

\section{CXCR2}

CXCR2 is expressed by many tumor cells and is involved in the chemotherapy resistance in different preclinical models of cancer. In breast cancer cells, CXCR2 deletion resulted in better response to Paclitaxel (68). In a melanoma model, the CXCR2 inhibitor Navarixin synergized with MEK inhibition (69) whereas, in an ovarian tumor model, the CXCR2 inhibitor SB225002 improved the antiangiogenic therapy Sorafenib (71). Finally, in human gastric cancer, Reparixin, a CXCR1 and CXCR2 inhibitor, enhanced the efficacy of 5-fluorouracil (72).

CXCR2 targeting inhibits tumor growth also because it affects myeloid cell infiltration. In pancreatic tumors, CXCR2 inhibition prevented the accumulation of neutrophils unleashing the $\mathrm{T}$ cell response (73), resulting in inhibition of metastatic spreading and improved response to anti-PD-1 (74). Interestingly, the combined treatment of CXCR2 and CCR2 inhibitors limited the compensatory response of TAMs, increased antitumor immunity and improved response to FX (75). Finally, in a prostate cancer model, CXCR2 inhibition by SB265610, decreased recruitment of myeloid cells and enhanced Docetaxel-induced senescence, limiting tumor growth (76).

Following these promising preclinical results, a phase II clinical trial with the CXCR2 inhibitor AZD5069 is ongoing in pancreatic cancer patients (NCT02583477). In addition, the safety of using Reparixin in combination with Paclitaxel was assessed (70) and a double-blind study with these drugs for metastatic triple-negative breast cancer is in progress (NCT02370238).

\section{CXCR4}

The CXCR4 antagonist AMD3100 (Plerixafor) is clinically approved for the mobilization of hematopoietic stem cells (HSCs) for transplantation in patients with Non-Hodgkin's lymphoma (NHL) or MM (67). Beside the HSCs mobilization effect, many preclinical data and clinical trials with AMD3100 or other CXCR4 inhibitors are now suggesting their effectiveness in tumors.

Referring to hematological malignancies, some CXCR4 antagonists, like AMD3100 and the derivative AMD3465, enhanced the efficacy of conventional therapies inducing the mobilization of cancer cells from the protective environment of the BM. In murine models of AML, AMD3100 improved the efficacy of chemotherapy with Ara-C (77). Similar results were obtained in a phase I/II study in patients with relapsed AML (78). The CXCR4 antagonists LY2510924 was also able to suppress the proliferation and progression of AML used as monotherapy (79). Another CXCR4 antagonist, BKT140 had an anti-leukemic effect in a murine model of NHL and its action was synergic with Rituximab (82). Phase I trials are ongoing to evaluate the safety and tolerability of the anti-CXCR4 mAbs BMS-936564 in AML patients (NCT01120457) and PF-06747143 in hematological malignancies (NCT02954653) (83).

CXCR4 inhibitors have strong antitumor and anti-metastatic effects also in solid tumors. In glioblastoma (GBM), CXCR4 expression is higher in more aggressive tumors and is further upregulated by anti-angiogenic therapies (85). AMD3465 reduced the growth of xenografts of glioblastoma multiforme and medulloblastoma cell lines (108) and the CXCR4 antagonist PRX177561, increased the antitumor effects of Bevacizumab and Sunitinib in subcutaneous or orthotopic xenografts of glioblastoma models (91). The CXCR4 antagonist POL5551 inhibited GBM growth and dissemination after anti-VEGF therapy (86). Current clinical trials with AMD3100 in newly diagnosed or recurrent GBM patients are evaluating the safety and efficacy of daily subcutaneous injection (NCI2012-00149) or 2 weeks continuous intravenous infusion (NCI2013-02012). A phase I/II study of the CXCR4 antagonist USL311 alone and in combination with Lomustine is ongoing in patients with advanced solid tumors and relapsed/recurrent glioblastoma multiforme (NCT02765165).

In addition to brain tumors, AMD3465 and LY2510924 have been found to inhibit tumor growth and metastatization in many preclinical models $(80,84)$. LY2510924, tested in a phase I trial (NCT02737072), was found clinically safe and well-tolerated in advanced solid cancers (colorectum, lung, breast, and prostate) (81). A phase I trial (NCT01837095) of the CXCR4 antagonist Balixafortide plus Eribulin in HER2-negative metastatic breast cancer has given promising results (88).

Notably, CXCR4 inhibition is not only acting on tumor cells but is also promoting antitumoral $\mathrm{T}$ cell responses. In a pancreas tumor model, AMD3100, blocking the interaction 
of CXCR4 positive tumor cells with CXCL12 producing fibroblasts, unleashed a rapid accumulation of $\mathrm{T}$ cells and acted synergistically with anti-PD-L1 (89). In a mesothelioma model, AMD3100 increased the efficiency of the vaccine against mesothelin (VIC-008) by inhibiting PD-1 expression on CD8 T cells and by converting $\mathrm{T}_{\text {regs }}$ in $\mathrm{T}$ helper like cells (90). The inhibition of $\mathrm{T}_{\text {regs }}$ infiltration and the promotion of antitumoral $\mathrm{T}$ cell response by AMD3100 were also demonstrated in a mouse model of ovarian cancer (87).

\section{THE ATYPICALS IN THE IMMUNOTHERAPY LANDSCAPE}

Atypical chemokine receptors (ACKRs) are emerging as crucial regulatory components of the chemokine network in a wide range of homeostatic and pathological conditions $(109,110)$. In this section, we reported preclinical observations and clinical data that provide evidences on their importance in cancer biology suggesting the possibility to validate them as new targets for innovative immunotherapies.

ACKR1 is mainly expressed on post-capillary and small collecting venular endothelial cells (ECs) and red blood cells (111), but also in many tumors such as GBM, hemangiosarcoma, erythroleukemia, breast, and colorectal cancers (112). It is able to bind a broad panel of both CC and CXC inflammatory chemokines acting as chemokine transporter. However, its role remains unclear in cancer because when expressed by ECs promotes tumor growth generating a chemokine gradient that sustains leukocyte infiltration (113). On the contrary, ACKR1 was reducing tumor growth in a model of prostate cancer (114) through the binding of angiogenic $\mathrm{ELR}^{+} \mathrm{CXC}$-chemokines that decreased angiogenesis and in a melanoma lung metastasis model, interacting with the tetraspanin CD82/KAI that induced tumor cells senescence (115). Finally, in breast carcinoma, ACKR1 expression correlated with a more favorable prognosis with less lymph nodes metastasis and better survival $(116,117)$.

ACKR2 plays a non-redundant role in the control of inflammatory response by scavenging and degrading most inflammatory CC chemokines, acting as agonists for receptors from CCR1 to CCR5 (118). It is expressed by trophoblast cells in placenta, lymphatic endothelial cells and at low levels by subsets of leukocytes $(92,119,120)$. ACKR2 acts as a tumor extrinsic suppressor gene. Indeed, by dampening inflammation, it has a protective role in different inflammation-driven tumor models $(121,122)$. ACKR2 prevents tumor growth also when it is expressed by Kaposi's sarcoma cells where it is downregulated by the oncogenic pathway KRAS/BRAF/MEK/MAPK (123), while in anaplastic thyroid carcinomas ACKR2 expression is downregulated by miR-146a (124). In both tumors ACKR2 downregulation unleashes pro-tumoral leukocyte infiltration.

On the contrary, ACKR2 has a tumor promoting role in the Apc-Min model of CRC limiting mast cells infiltration and activation of $\mathrm{CD}^{+} \mathrm{T}$ cells (125) and it has a pro-metastatic function in breast and melanoma cancer models, by limiting neutrophil and NK activity $(92,93)$.
ACKR3, is a high affinity receptor for CXCL12 and CXCL11 expressed by hematopoietic cells, mesenchymal cells, activated ECs, and neurons. ACKR3 negatively regulates CXCL11 and CXCL12 bioavailability and modulates CXCR4 expression and function $(126,127)$. In cancer, ACKR3 was found expressed on many tumor cells (such as renal carcinoma, breast cancer, and glioblastoma) and by tumoral ECs. It promotes tumor cell growth and metastasis $(128,129)$ acting on mTOR pathway $(130)$. In lung adenocarcinoma, ACKR3 mediates TGF- $B 1$ promoted epithelial to mesenchymal transition (EMT) and tumor growth (131). ACKR3 is also expressed by aggressive prostate carcinoma cells (132) and in renal carcinoma patients with decreased survival and poor prognosis. In renal cell carcinoma, ACKR3 expressed by endothelial progenitor cells and tumoral ECs exerts a proangiogenic role inducing their migration and survival (133). In a glioblastoma murine model, mice treated with $\mathrm{X} 7 \mathrm{Ab}$ against ACKR3 in combination with Temozolomide (TMZ) showed significant tumor reduction and longer survival, enhancing M1 macrophage activation (94).

The last member of the family, ACKR4 is a scavenger receptor for CCL19, CCL21, CCL25, and CXCL13. It is expressed by keratinocytes, thymic epithelium and bronchial cells (134). Some papers indicated a protective role of ACKR4 in tumors. In HCC tumors, it impaired chemotactic events associated with CCR7, limiting tumor progression and metastasis (135). ACKR4 downregulation in human breast and colon cancer correlated with a worse outcome $(136,137)$. However, in breast carcinoma ACKR4 had a pro-metastatic role regulating EMT (138).

\section{CONCLUDING REMARKS}

Being chemokines and chemokine receptors expressed by both tumor cells and leukocyte infiltrate they represent an ideal target for immunotherapy. However, better understanding of their roles in different malignancies is still necessary to avoid potential side effects. In hematological malignancies targeting of overexpressed chemokine receptors directly kill tumor cells but can potentially induce unwanted immune reactions (e.g., CCR4).

In the context of solid tumors, chemokine receptor inhibitors are giving encouraging results when used in combination with chemotherapy or with antibodies against immune checkpoints. For this reason, it is possible to envisage that chemokine receptor inhibitors will be used in the future to modulate the stromal component, to overcome chemotherapy resistance and to optimize the immune response of the patients.

\section{AUTHOR CONTRIBUTIONS}

VMP wrote the initial draft. AC, MM, and RB made substantial contributions and discussed the content. All authors reviewed and/or edited the manuscript prior submission.

\section{ACKNOWLEDGMENTS}

This study was supported by the Italian Association for Cancer Research AIRC-IG 20269 to RB and AIRC 5x1000-21147-ISM. 


\section{REFERENCES}

1. Mantovani A, Allavena P, Sica A, Balkwill F. Cancer-related inflammation. Nature. (2008) 454:436-44. doi: 10.1038/nature07205

2. Colotta F, Allavena P, Sica A, Garlanda C, Mantovani A. Cancer-related inflammation, the seventh hallmark of cancer, links to genetic instability. Carcinogenesis. (2009) 30:1073-81. doi: 10.1093/carcin/bgp127

3. Griffith JW, Sokol CL, Luster AD. Chemokines and chemokine receptors, positioning cells for host defense and immunity. Annu Rev Immunol. (2014) 32:659-702. doi: 10.1146/annurev-immunol-032713-120145

4. Mantovani A, Savino B, Locati M, Zammataro L, Allavena P, Bonecchi R. The chemokine system in cancer biology and therapy. Cytokine Growth Factor Rev. (2010) 21:27-39. doi: 10.1016/j.cytogfr.2009.11.007

5. Caronni N, Savino B, Recordati C, Villa A, Locati M, Bonecchi R. Cancer and chemokines. Methods Mol Biol. (2016) 1393:87-96. doi: 10.1007/978-1-4939-3338-9_8

6. Chow MT, Luster AD. Chemokines in cancer. Cancer Immunol Res. (2014) 2:1125-31. doi: 10.1158/2326-6066.CIR-14-0160

7. Balkwill FR. The chemokine system and cancer. J Pathol. (2012) 226:148-57. doi: 10.1002 /path.3029

8. Caronni N, Savino B, Bonecchi R. Myeloid cells in cancerrelated inflammation. Immunobiology. (2015) 220:249-53. doi: 10.1016/j.imbio.2014.10.001

9. Bonavita O, Massara M, Bonecchi R. Chemokine regulation of neutrophil function in tumors. Cytokine Growth Factor Rev. (2016) 30:81-6. doi: 10.1016/j.cytogfr.2016.03.012

10. Massara M, Persico P, Bonavita O, Mollica Poeta V, Locati M, Simonelli $\mathrm{M}$, et al. Neutrophils in Gliomas. Front Immunol. (2017) 8:1349. doi: 10.3389/fimmu.2017.01349

11. Cho SW, Kim YA, Sun HJ, Kim YA, Oh BC, Yi KH, et al. CXCL16 signaling mediated macrophage effects on tumor invasion of papillary thyroid carcinoma. Endocr Relat Cancer. (2016) 23:113-24. doi: 10.1530/ERC-15-0196

12. Lepore F, D'Alessandro G, Antonangeli F, Santoro A, Esposito V, Limatola C, et al. CXCL16/CXCR6 axis drives microglia/macrophages phenotype in physiological conditions and plays a crucial role in glioma. Front Immunol. (2018) 9:2750. doi: 10.3389/fimmu.2018.02750

13. Wendel M, Galani IE, Suri-Payer E, Cerwenka A. Natural killer cell accumulation in tumors is dependent on IFN-gamma and CXCR3 ligands. Cancer Res. (2008) 68:8437-45. doi: 10.1158/0008-5472.CAN-08-1440

14. Hensbergen PJ, Wijnands PG, Schreurs MW, Scheper RJ, Willemze R, Tensen CP, et al. The CXCR3 targeting chemokine CXCL11 has potent antitumor activity in vivo involving attraction of $\mathrm{CD}^{+}{ }^{+} \mathrm{T}$ lymphocytes but not inhibition of angiogenesis. J Immunother. (2005) 28:343-51. doi: 10.1097/01.cji.0000165355.26795.27

15. Scarpino S, Stoppacciaro A, Ballerini F, Marchesi M, Prat M, Stella MC, et al. Papillary carcinoma of the thyroid, hepatocyte growth factor (HGF) stimulates tumor cells to release chemokines active in recruiting dendritic cells. Am J Pathol. (2000) 156:831-7. doi: 10.1016/S0002-9440(10)64951-6

16. Correale P, Rotundo MS, Botta C, Del Vecchio MT, Tassone P, Tagliaferri P. Tumor infiltration by chemokine receptor 7 (CCR7) $(+)$ Tlymphocytes is a favorable prognostic factor in metastatic colorectal cancer. Oncoimmunology. (2012) 1:531-2. doi: 10.4161/onci.19404

17. Mburu YK, Wang J, Wood MA, Walker WH, Ferris RL. CCR7 mediates inflammation-associated tumor progression. Immunol Res. (2006) 36:61-72. doi: 10.1385/IR:36:1:61

18. Gobert M, Treilleux I, Bendriss-Vermare N, Bachelot T, Goddard-Leon $\mathrm{S}$, Arfi V, et al. Regulatory $\mathrm{T}$ cells recruited through CCL22/CCR4 are selectively activated in lymphoid infiltrates surrounding primary breast tumors and lead to an adverse clinical outcome. Cancer Res. (2009) 69:20009. doi: 10.1158/0008-5472.CAN-08-2360

19. Ridiandries A, Tan J, Bursill CA. The Role of CC-chemokines in the regulation of angiogenesis. Int J Mol Sci. (2016) 17:1856. doi: 10.3390/ijms17111856

20. Santoni M, Bracarda S, Nabissi M, Massari F, Conti A, Bria E, et al. CXC and $\mathrm{CC}$ chemokines as angiogenic modulators in nonhaematological tumors. Biomed Res Int. (2014) 2014:768758. doi: 10.1155/2014/768758
21. Keeley EC, Mehrad B, Strieter RM. CXC chemokines in cancer angiogenesis and metastases. Adv Cancer Res. (2010) 106:91-111. doi: 10.1016/S0065-230X(10)06003-3

22. Lin L, Chen YS, Yao YD, Chen JQ, Chen JN, Huang SY, et al. CCL18 from tumor-associated macrophages promotes angiogenesis in breast cancer. Oncotarget. (2015) 6:34758-73. doi: 10.18632/oncotarget.5325

23. Yu X, Zhao R, Lin S, Bai X, Zhang L, Yuan S, et al. CXCL16 induces angiogenesis in autocrine signaling pathway involving hypoxia-inducible factor 1alpha in human umbilical vein endothelial cells. Oncol Rep. (2016) 35:1557-65. doi: 10.3892/or.2015.4520

24. Sozzani S, Del Prete A, Bonecchi R, Locati M. Chemokines as effector and target molecules in vascular biology. Cardiovasc Res. (2015) 107:364-72. doi: $10.1093 / \mathrm{cvr} / \mathrm{cvv} 150$

25. Kryczek I, Lange A, Mottram P, Alvarez X, Cheng P, Hogan M, et al. CXCL12 and vascular endothelial growth factor synergistically induce neoangiogenesis in human ovarian cancers. Cancer Res. (2005) 65:465-72.

26. Strieter RM, Burdick MD, Gomperts BN, Belperio JA, Keane MP. CXC chemokines in angiogenesis. Cytokine Growth Factor Rev. (2005) 16:593-609. doi: 10.1016/j.cytogfr.2005.04.007

27. Lau TS, Chung TK, Cheung TH, Chan LK, Cheung LW, Yim SF, et al. Cancer cell-derived lymphotoxin mediates reciprocal tumour-stromal interactions in human ovarian cancer by inducing CXCL11 in fibroblasts. J Pathol. (2014) 232:43-56. doi: 10.1002/path.4258

28. Mishra P, Banerjee D, Ben-Baruch A. Chemokines at the crossroads of tumor-fibroblast interactions that promote malignancy. J Leukoc Biol. (2011) 89:31-9. doi: 10.1189/jlb.0310182

29. Teicher BA, Fricker SP. CXCL12 (SDF-1)/CXCR4 pathway in cancer. Clin Cancer Res. (2010) 16:2927-31. doi: 10.1158/1078-0432.CCR-09-2329

30. Balkwill F. Cancer and the chemokine network. Nat Rev Cancer. (2004) 4:540-50. doi: 10.1038/nrc1388

31. Liang K, Liu Y, Eer D, Liu J, Yang F, Hu K. High CXC chemokine ligand 16 (CXCL16) expression promotes proliferation and metastasis of lung cancer via regulating the NF-kappaB pathway. Med Sci Monit. (2018) 24:405-11. doi: 10.12659/MSM.906230

32. Murakami T, Cardones AR, Finkelstein SE, Restifo NP, Klaunberg BA, Nestle FO, et al. Immune evasion by murine melanoma mediated through CC chemokine receptor-10. J Exp Med. (2003) 198:1337-47. doi: 10.1084/jem.20030593

33. Smith MC, Luker KE, Garbow JR, Prior JL, Jackson E, Piwnica-Worms D, et al. CXCR4 regulates growth of both primary and metastatic breast cancer. Cancer Res. (2004) 64:8604-12. doi: 10.1158/0008-5472.CAN-04-1844

34. Zlotnik A, Burkhardt AM, Homey B. Homeostatic chemokine receptors and organ-specific metastasis. Nat Rev Immunol. (2011) 11:597-606. doi: $10.1038 /$ nri3049

35. Takanami I. Overexpression of CCR7 mRNA in nonsmall cell lung cancer, correlation with lymph node metastasis. Int J Cancer. (2003) 105:186-9. doi: $10.1002 /$ ijc. 11063

36. Ben-Baruch A. Organ selectivity in metastasis, regulation by chemokines and their receptors. Clin Exp Metastasis. (2008) 25:345-56. doi: 10.1007/s10585-007-9097-3

37. Yang XL, Liu KY, Lin FJ, Shi HM, Ou ZL. CCL28 promotes breast cancer growth and metastasis through MAPK-mediated cellular anti-apoptosis and pro-metastasis. Oncol Rep. (2017) 38:1393-401. doi: 10.3892/or. 2017.5798

38. Lillard J, Singh R, Sharma P, Singh S. CXCL13 inhibition prevents bone metastasis in hormone-refractory prostate cancer (133.8). J Immunol. (2010) 184(Suppl 1) 133:8.

39. Darash-Yahana M, Pikarsky E, Abramovitch R, Zeira E, Pal B, Karplus R, et al. Role of high expression levels of CXCR4 in tumor growth, vascularization, and metastasis. FASEB J. (2004) 18:1240-2. doi: 10.1096/fj.03-0935fje

40. Papaioannou NE, Beniata OV, Vitsos P, Tsitsilonis O, Samara P. Harnessing the immune system to improve cancer therapy. Ann Transl Med. (2016) 4:261. doi: 10.21037/atm.2016.04.01

41. Chaudhuri D, Suriano R, Mittelman A, Tiwari RK. Targeting the immune system in cancer. Curr Pharm Biotechnol. (2009) 10:166-84. doi: $10.2174 / 138920109787315114$ 
42. Balkwill FR, Mantovani A. Cancer-related inflammation, common themes and therapeutic opportunities. Semin Cancer Biol. (2012) 22:33-40. doi: 10.1016/j.semcancer.2011.12.005

43. Moynihan KD, Irvine DJ. Irvine, roles for innate immunity in combination immunotherapies. Cancer Res. (2017) 77:5215-21. doi: 10.1158/0008-5472.CAN-17-1340

44. Dairaghi DJ, Oyajobi BO, Gupta A, McCluskey B, Miao S, Powers JP, et al. CCR1 blockade reduces tumor burden and osteolysis in vivo in a mouse model of myeloma bone disease. Blood. (2012) 120:1449-57. doi: 10.1182/blood-2011-10-384784

45. Vallet S, Raje N, Ishitsuka K, Hideshima T, Podar K, Chhetri S, et al. MLN3897, a novel CCR1 inhibitor, impairs osteoclastogenesis and inhibits the interaction of multiple myeloma cells and osteoclasts. Blood. (2007) 110:3744-52. doi: 10.1182/blood-2007-05-093294

46. Kitamura T, Fujishita T, Loetscher P, Revesz L, Hashida H, Kizaka-Kondoh S, et al. Inactivation of chemokine (C-C motif) receptor 1 (CCR1) suppresses colon cancer liver metastasis by blocking accumulation of immature myeloid cells in a mouse model. Proc Natl Acad Sci USA. (2010) 107:13063-8. doi: 10.1073/pnas.1002372107

47. Jung H, Bischof A, Ebsworth K, Ertl L, Schall T, Charo I. Combination therapy of chemokine receptor inhibition plus PDL-1 blockade potentiates anti-tumor effects in a murine model of breast cancer. J Immunother Cancer. (2015) 3:P227. doi: 10.1186/2051-1426-3-S2-P227

48. Mitchem JB, Brennan DJ, Knolhoff BL, Belt BA, Zhu Y, Sanford DE, et al. Targeting tumor-infiltrating macrophages decreases tumor-initiating cells, relieves immunosuppression, and improves chemotherapeutic responses. Cancer Res. (2013) 73:1128-41. doi: 10.1158/0008-5472.CAN-12-2731

49. Noel M, Lowery M, Ryan D, Wolpin B, Bullock A, Britten C, et al. 750PPhase Ib study of PF-04136309 (an oral CCR2 inhibitor) in combination with nab-paclitaxel/gemcitabine in first-line treatment of metastatic pancreatic adenocarcinoma. Annals Oncol. (2017) 28(Suppl 5):209-68. doi: 10.1093/annonc/mdx369.132

50. Jung H, Ertl L, Janson C, Schall T, Charo I. Abstract A107, Inhibition of CCR2 potentiates the checkpoint inhibitor immunotherapy in pancreatic cancer. Cancer Immunol Res. (2016) 4(Suppl. 11):A107. doi: 10.1158/2326-6066.IMM2016-A107

51. Nywening TM, Wang-Gillam A, Sanford DE, Belt BA, Panni RZ, Cusworth BM, et al. Targeting tumour-associated macrophages with CCR2 inhibition in combination with FOLFIRINOX in patients with borderline resectable and locally advanced pancreatic cancer, a single-centre, open-label, dosefinding, non-randomised, phase 1b trial. Lancet Oncol. (2016) 17:651-62. doi: 10.1016/S1470-2045(16)00078-4

52. Li X, Yao W, Yuan Y, Chen P, Li B, Li J, et al. Targeting of tumourinfiltrating macrophages via CCL2/CCR2 signalling as a therapeutic strategy against hepatocellular carcinoma. Gut. (2017) 66:157-67. doi: 10.1136/gutjnl-2015-310514

53. Linehan D, Smith Noel M, Hezel AF, Wang-Gillam A, Eskens F, Sleijfer S, et al. Overall survival in a trial of orally administered CCR2 inhibitor CCX872 in locally advanced/metastatic pancreatic cancer, Correlation with blood monocyte counts. J Clin Oncol. (2018) 36:92. doi: 10.1200/JCO.2018.36.5_suppl.92

54. Yao W, Ba Q, Li X, Li H, Zhang S, Yuan Y, et al. A natural CCR2 antagonist relieves tumor-associated macrophage-mediated immunosuppression to produce a therapeutic effect for liver cancer. EBioMed. (2017) 22:58-67. doi: 10.1016/j.ebiom.2017.07.014

55. Binder P, Cullinan D, Wilkinson-Ryan I, Goedegebuure P, Powell MA, Mutch $\mathrm{DG}$, et al. CCR2 blockade alters the tumor microenvironment immune infiltrate and enhances anti-tumor activity in ovarian cancer. Gynecol Oncol. (2017) 145:36. doi: 10.1016/j.ygyno.2017.03.094

56. Bonapace L, Coissieux MM, Wyckoff J, Mertz KD, Varga Z, Junt T, et al. Cessation of CCL2 inhibition accelerates breast cancer metastasis by promoting angiogenesis. Nature. (2014) 515:130-3. doi: 10.1038/nature 13862

57. Pienta KJ, Machiels JP, Schrijvers D, Alekseev B, Shkolnik M, Crabb SJ, et al. Phase 2 study of carlumab (CNTO 888), a human monoclonal antibody against CC-chemokine ligand 2 (CCL2), in metastatic castration-resistant prostate cancer. Invest New Drugs. (2013) 31:760-8. doi: $10.1007 /$ s10637-012-9869-8
58. Sandhu SK, Papadopoulos K, Fong PC, Patnaik A, Messiou C, Olmos D, et al. A first-in-human, first-in-class, phase I study of carlumab (CNTO 888), a human monoclonal antibody against CC-chemokine ligand 2 in patients with solid tumors. Cancer Chemother Pharmacol. (2013) 71:104150. doi: 10.1007/s00280-013-2099-8

59. Perera LP, Zhang M, Nakagawa M, Petrus MN, Maeda M, Kadin ME, et al. Chimeric antigen receptor modified $\mathrm{T}$ cells that target chemokine receptor CCR4 as a therapeutic modality for T-cell malignancies. Am J Hematol. (2017) 92:892-901. doi: 10.1002/ajh.24794

60. Fuji S, Utsunomiya A, Inoue Y, Miyagi T, Owatari S, Sawayama Y, et al. Outcomes of patients with relapsed aggressive adult T-cell leukemialymphoma, clinical effectiveness of anti-CCR4 antibody and allogeneic hematopoietic stem cell transplantation. Haematologica. (2018) 103:e211-4. doi: 10.3324/haematol.2017.184564

61. Berlato C, Khan MN, Schioppa T, Thompson R, Maniati E, Montfort A, et al. A CCR4 antagonist reverses the tumor-promoting microenvironment of renal cancer. J Clin Invest. (2017) 127:801-13. doi: 10.1172/JCI82976

62. Beziaud L, Boullerot L, Tran T, Mansi L, Marie-Joseph EL, Ravel P, et al. Rapalog combined with CCR4 antagonist improves anticancer vaccines efficacy. Int J Cancer. (2018) 143:3008-18. doi: 10.1002/ijc.31842

63. Rose S. Mogamulizumab tops standard of care for CTCL. Cancer Discov. (2018) 8:1. doi: 10.1158/2159-8290.CD-NB2018-001

64. Halama N, Zoernig I, Berthel A, Kahlert C, Klupp F, Suarez-Carmona M, et al. Tumoral Immune cell exploitation in colorectal cancer metastases can be targeted effectively by anti-CCR 5 therapy in cancer patients. Cancer Cell. (2016) 29:587-601. doi: 10.1016/j.ccell.2016.03.005

65. Yu S, Duan J, Zhou Z, Pang Q, Wuyang J, Liu T, et al. A critical role of CCR7 in invasiveness and metastasis of SW620 colon cancer cell in vitro and in vivo. Cancer Biol Ther. (2008) 7:1037-43. doi: 10.4161/cbt.7.7.6065

66. Chi BJ, Du CL, Fu YF, Zhang YN, Wang RW. Silencing of CCR7 inhibits the growth, invasion and migration of prostate cancer cells induced by VEGFC. Int J Clin Exp Pathol. (2015) 8:12533-40. Available online at: http://www. ijcep.com/files/ijcep0014636.pdf

67. Micallef IN, Stiff PJ, Nademanee AP, Maziarz RT, Horwitz ME, Stadtmauer EA, et al. Plerixafor plus granulocyte colony-stimulating factor for patients with non-hodgkin lymphoma and multiple myeloma, long-term follow-up report. Biol Blood Marrow Transplant. (2018) 24:1187-95. doi: 10.1016/j.bbmt.2018.01.039

68. Sharma B, Nawandar DM, Nannuru KC, Varney ML, Singh RK. Targeting CXCR2 enhances chemotherapeutic response, inhibits mammary tumor growth, angiogenesis, and lung metastasis. Mol Cancer Ther. (2013) 12:799808. doi: 10.1158/1535-7163.MCT-12-0529

69. Young HL, Rowling EJ, Bugatti M, Giurisato E, Luheshi N, Arozarena I, et al. An adaptive signaling network in melanoma inflammatory niches confers tolerance to MAPK signaling inhibition. J Exp Med. (2017) 214:1691-710. doi: $10.1084 /$ jem.20160855

70. Schott AF, Goldstein LJ, Cristofanilli M, Ruffini PA, McCanna S, Reuben $\mathrm{JM}$, et al. Phase Ib pilot study to evaluate reparixin in combination with weekly paclitaxel in patients with HER-2-negative metastatic breast cancer. Clin Cancer Res. (2017) 23:5358-65. doi: 10.1158/1078-0432.CCR-16-2748

71. Devapatla B, Sharma A, Woo S. CXCR2 inhibition combined with sorafenib improved antitumor and antiangiogenic response in preclinical models of ovarian cancer. PLOS ONE. (2015) 10:e0139237. doi: 10.1371/journal.pone.0139237

72. Wang J, Hu W, Wang K, Yu J, Luo B, Luo G, et al. Repertaxin, an inhibitor of the chemokine receptors CXCR1 and CXCR2, inhibits malignant behavior of human gastric cancer MKN45 cells in vitro and in vivo and enhances efficacy of 5-fluorouracil. Int J Oncol. (2016) 48:1341-52. doi: 10.3892/ijo.2016.3371

73. Chao T, Furth EE, Vonderheide RH. CXCR2-dependent accumulation of tumor-associated neutrophils regulates T-cell immunity in pancreatic ductal adenocarcinoma. Cancer Immunol Res. (2016) 4:968-82. doi: 10.1158/2326-6066.CIR-16-0188

74. Steele CW, Karim SA, Leach JDG, Bailey P, Upstill-Goddard R, Rishi L, et al. CXCR2 Inhibition profoundly suppresses metastases and augments immunotherapy in pancreatic ductal adenocarcinoma. Cancer Cell. (2016) 29:832-45. doi: 10.1016/j.ccell.2016.04.014

75. Nywening TM, Belt BA, Cullinan DR, Panni RZ, Han BJ, Sanford DE, et al. Targeting both tumour-associated $\mathrm{CXCR}^{+}{ }^{+}$neutrophils and CCR2 ${ }^{+}$ 
macrophages disrupts myeloid recruitment and improves chemotherapeutic responses in pancreatic ductal adenocarcinoma. Gut. (2018) 67:1112-23. doi: 10.1136/gutjnl-2017-313738

76. Di Mitri D, Toso A, Chen JJ, Sarti M, Pinton S, Jost TR, et al. Tumourinfiltrating Gr-1+ myeloid cells antagonize senescence in cancer. Nature. (2014) 515:134-7. doi: 10.1038/nature13638

77. Nervi B, Ramirez P, Rettig MP, Uy GL, Holt MS, Ritchey JK, et al. Chemosensitization of acute myeloid leukemia (AML) following mobilization by the CXCR4 antagonist AMD3100. Blood. (2009) 113:6206-14. doi: 10.1182/blood-2008-06-162123

78. Uy GL, Rettig MP, Motabi IH, McFarland K, Trinkaus KM, Hladnik LM, et al. A phase 1/2 study of chemosensitization with the CXCR4 antagonist plerixafor in relapsed or refractory acute myeloid leukemia. Blood. (2012) 119:3917-24. doi: 10.1182/blood-2011-10-383406

79. Cho BS, Zeng Z, Mu H, Wang Z, Konoplev S, McQueen T, et al. Antileukemia activity of the novel peptidic CXCR4 antagonist LY2510924 as monotherapy and in combination with chemotherapy. Blood. (2015) 126:222-32. doi: 10.1182/blood-2015-02-628677

80. Peng SB, Zhang X, Paul D, Kays LM, Gough W, Stewart J, et al. Identification of LY2510924, a novel cyclic peptide CXCR4 antagonist that exhibits antitumor activities in solid tumor and breast cancer metastatic models. Mol Cancer Ther. (2015) 14:480-90. doi: 10.1158/1535-7163.MCT-14-0850

81. Galsky MD, Vogelzang NJ, Conkling P, Raddad E, Polzer J, Roberson S, et al. A phase I trial of LY2510924, a CXCR4 peptide antagonist, in patients with advanced cancer. Clin Cancer Res. (2014) 20:3581-8. doi: 10.1158/1078-0432.CCR-13-2686

82. Beider K, Ribakovsky E, Abraham M, Wald H, Weiss L, Rosenberg E, et al. Targeting the CD20 and CXCR4 pathways in non-hodgkin lymphoma with rituximab and high-affinity CXCR4 antagonist BKT140. Clin Cancer Res. (2013) 19:3495-507. doi: 10.1158/1078-0432.CCR-12-3015

83. Liu SH, Gu Y, Pascual B, Yan Z, Hallin M, Zhang C, et al. A novel CXCR4 antagonist IgG1 antibody (PF-06747143) for the treatment of hematologic malignancies. Blood Adv. (2017) 1:1088-100. doi: 10.1182/bloodadvances.2016003921

84. Ling X, Spaeth E, Chen Y, Shi Y, Zhang W, Schober W, et al. The CXCR4 antagonist AMD3465 regulates oncogenic signaling and invasiveness in vitro and prevents breast cancer growth and metastasis in vivo. PLoS ONE. (2013) 8:e58426. doi: 10.1371/journal.pone.0058426

85. Pham K, Luo D, Siemann DW, Law BK, Reynolds BA, Hothi P, et al. VEGFR inhibitors upregulate CXCR4 in VEGF receptor-expressing glioblastoma in a TGFbetaR signaling-dependent manner. Cancer Lett. (2015) 360:60-7. doi: 10.1016/j.canlet.2015.02.005

86. Gagner JP, Sarfraz Y, Ortenzi V, Alotaibi FM, Chiriboga LA, Tayyib AT, et al. Multifaceted C-X-C chemokine receptor 4 (CXCR4) inhibition interferes with anti-vascular endothelial growth factor therapyinduced glioma dissemination. Am J Pathol. (2017) 187:2080-94. doi: 10.1016/j.ajpath.2017.04.020

87. Righi E, Kashiwagi S, Yuan J, Santosuosso M, Leblanc P, Ingraham R, et al. CXCL12/CXCR4 blockade induces multimodal antitumor effects that prolong survival in an immunocompetent mouse model of ovarian cancer. Cancer Res. (2011) 71:5522-34. doi: 10.1158/0008-5472.CAN-10-3143

88. Pernas S, Martin M, Kaufman PA, Gil-Martin M, Gomez Pardo P, LopezTarruella S, et al. Balixafortide plus eribulin in HER2-negative metastatic breast cancer, a phase 1, single-arm, dose-escalation trial. Lancet Oncol. (2018) 19:812-24. doi: 10.1016/S1470-2045(18)30147-5

89. Feig C, Jones JO, Kraman M, Wells RJ, Deonarine A, Chan DS, et al. Targeting CXCL12 from FAP-expressing carcinoma-associated fibroblasts synergizes with anti-PD-L1 immunotherapy in pancreatic cancer. Proc Natl Acad Sci USA. (2013) 110:20212-7. doi: 10.1073/pnas.1320318110

90. Li B, Zeng Y, Reeves PM, Ran C, Liu Q, Qu X, et al. AMD3100 augments the efficacy of mesothelin-targeted, immune-activating VIC-008 in mesothelioma by modulating intratumoral immunosuppression. Cancer Immunol Res. (2018) 6:539-51. doi: 10.1158/2326-6066.CIR-17-0530

91. Gravina GL, Mancini A, Marampon F, Colapietro A, Delle Monache S, Sferra R, et al. The brain-penetrating CXCR4 antagonist, PRX177561, increases the antitumor effects of bevacizumab and sunitinib in preclinical models of human glioblastoma. J Hematol Oncol. (2017) 10:5. doi: $10.1186 / s 13045-016-0377-8$
92. Massara M, Bonavita O, Savino B, Caronni N, Mollica Poeta V, Sironi $\mathrm{M}$, et al. ACKR2 in hematopoietic precursors as a checkpoint of neutrophil release and anti-metastatic activity. Nat Commun. (2018) 9:676. doi: 10.1038/s41467-018-03080-8

93. Hansell CAH, Fraser AR, Hayes AJ, Pingen M, Burt CL, Lee KM, et al. The atypical chemokine receptor Ackr2 constrains NK cell migratory activity and promotes metastasis. J Immunol. (2018) 201:2510-9. doi: 10.4049/jimmunol.1800131

94. Salazar N, Carlson JC, Huang K, Zheng Y, Oderup C, Gross J, et al. A chimeric antibody against ACKR3/CXCR7 in combination with TMZ activates immune responses and extends survival in mouse GBM models. Mol Ther. (2018) 26:1354-65. doi: 10.1016/j.ymthe.2018.02.030

95. Oyajobi BO, Franchin G, Williams PJ, Pulkrabek D, Gupta A, Munoz S, et al. Dual effects of macrophage inflammatory protein-1alpha on osteolysis and tumor burden in the murine 5TGM1 model of myeloma bone disease. Blood. (2003) 102:311-9. doi: 10.1182/blood-2002-12-3905

96. Horuk R. Chemokine receptor antagonists, overcoming developmental hurdles. Nat Rev Drug Discov. (2009) 8:23-33. doi: 10.1038/nrd2734

97. Cullis J, Siolas D, Avanzi A, Barui S, Maitra A, Bar-Sagi D. Macropinocytosis of Nab-paclitaxel drives macrophage activation in pancreatic cancer. Cancer Immunol Res. (2017) 5:182-90. doi: 10.1158/2326-6066.CIR-16-0125

98. Yao M, Fang W, Smart C, Hu Q, Huang S, Alvarez N, et al. CCR2 chemokine receptors enhance growth and cell cycle progression of breast cancer cells through SRC and PKC activation. Mol Cancer Res. (2018) 17:604-17. doi: 10.1158/1541-7786.MCR-18-0750

99. Lu Y, Cai Z, Xiao G, Liu Y, Keller ET, Yao Z, et al. CCR2 expression correlates with prostate cancer progression. J Cell Biochem. (2007) 101:67685. doi: $10.1002 /$ jcb. 21220

100. Kalbasi A, Komar C, Tooker GM, Liu M, Lee JW, Gladney WL, et al. Tumor-derived CCL2 mediates resistance to radiotherapy in pancreatic ductal adenocarcinoma. Clin Cancer Res. (2017) 23:137-48. doi: 10.1158/1078-0432.CCR-16-0870

101. Allison SJ. Kidney cancer, CCR4, a new target for RCC. Nat Rev Nephrol. (2017) 13:192. doi: 10.1038/nrneph.2017.14

102. Fuji S, Shindo T. Friend or foe? Mogamulizumab in allogeneic hematopoietic stem cell transplantation for adult T-cell leukemia/lymphoma. Stem Cell Investig. (2016) 3:70. doi: 10.21037/sci.2016.09.13

103. González-Martín A, Mira E, Ma-es S. CCR5 in cancer immunotherapy, More than an "attractive" receptor for T cells. Oncoimmunology. (2012) 1:106-8. doi: 10.4161/onci.1.1.17995

104. Velasco-Velazquez M, Xolalpa W, Pestell RG. The potential to target CCL5/CCR5 in breast cancer. Exp Opin Ther Targets. (2014) 18:1265-75. doi: 10.1517/14728222.2014.949238

105. Hawila E, Razon H, Wildbaum G, Blattner C, Sapir Y, Shaked Y, et al. CCR5 directs the mobilization of $\mathrm{CD} 11 \mathrm{~b}(+) \mathrm{Gr} 1(+) \mathrm{Ly} 6 \mathrm{C}(\mathrm{low})$ polymorphonuclear myeloid cells from the bone marrow to the blood to support tumor development. Cell Rep. (2017) 21:2212-22. doi: 10.1016/j.celrep.2017. 10.104

106. Kim SJ, Shin JY, Lee KD, Bae YK, Sung KW, Nam SJ, et al. MicroRNA let-7a suppresses breast cancer cell migration and invasion through downregulation of C-C chemokine receptor type 7. Breast Cancer Res. (2012) 14:R14. doi: 10.1186/bcr3098

107. Cunningham H, Kim E, August K, Vines C. 948onovel single chain antibodies to inhibit Ccr7 mediated-entry of pediatric T-cell acute lymphoblastic leukemia into the Cns. Ann Oncol. (2014) 25(Suppl. 4):iv328. doi: 10.1093/annonc/mdu339.5

108. Yang L, Jackson E, Woerner BM, Perry A, Piwnica-Worms D, Rubin JB. Blocking CXCR4-mediated cyclic AMP suppression inhibits brain tumor growth in vivo. Cancer Res. (2007) 67:651-8. doi: 10.1158/0008-5472.CAN-06-2762

109. Massara M, Bonavita O, Mantovani A, Locati M, Bonecchi R. Atypical chemokine receptors in cancer, friends or foes? J Leukoc Biol. (2016) 99:92733. doi: 10.1189/jlb.3MR0915-431RR

110. Mantovani A, Bonecchi R, Locati M. Tuning inflammation and immunity by chemokine sequestration, decoys and more. Nat Rev Immunol. (2006) 6:907-18. doi: 10.1038/nri1964

111. Thiriot A, Perdomo C, Cheng G, Novitzky-Basso I, McArdle S, Kishimoto JK, et al. Differential DARC/ACKR1 expression distinguishes venular from 
non-venular endothelial cells in murine tissues. BMC Biol. (2017) 15:45. doi: 10.1186/s12915-017-0381-7

112. Horuk R. The duffy antigen receptor for chemokines DARC/ACKR1. Front Immunol. (2015) 6:279. doi: 10.3389/fimmu.2015.00279

113. Addison CL, Belperio JA, Burdick MD, Strieter RM. Overexpression of the duffy antigen receptor for chemokines (DARC) by NSCLC tumor cells results in increased tumor necrosis. BMC Cancer. (2004) 4:28. doi: 10.1186/1471-2407-4-28

114. Shen H, Schuster R, Stringer KF, Waltz SE, Lentsch AB. The duffy antigen/receptor for chemokines (DARC) regulates prostate tumor growth. FASEB J. (2006) 20:59-64. doi: 10.1096/fj.05-4764com

115. Khanna P, Chung CY, Neves RI, Robertson GP, Dong C. CD82/KAI expression prevents IL-8-mediated endothelial gap formation in latestage melanomas. Oncogene. (2014) 33:2898-908. doi: 10.1038/onc. 2013.249

116. Wang J, Ou ZL, Hou YF, Luo JM, Shen ZZ, Ding J, et al. Enhanced expression of Duffy antigen receptor for chemokines by breast cancer cells attenuates growth and metastasis potential. Oncogene. (2006) 25:7201-11. doi: 10.1038/sj.onc.1209703

117. Jenkins BD, Hire R, Howerth E, Monteil M, Martini R, Davis MB, et al. Atypical chemokine receptor 1 (ACKR1/DARC) expressing tumors are associated with distinct recruitment of immune cells and increased pro-inflammatory chemokines. AACR. (2017) 77(Suppl.13):953. doi: 10.1158/1538-7445.AM2017-953

118. Bonecchi $R$, Locati $M$, Galliera E, Vulcano $M$, Sironi $M$, Fra AM, et al. Differential recognition and scavenging of native and truncated macrophage-derived chemokine (macrophage-derived chemokine/CC chemokine ligand 22) by the D6 decoy receptor. J Immunol. (2004) 172:4972-6. doi: 10.4049/jimmunol.172.8.4972

119. Nibbs RJ, Kriehuber E, Ponath PD, Parent D, Qin S, Campbell JD, et al. The beta-chemokine receptor D6 is expressed by lymphatic endothelium and a subset of vascular tumors. Am J Pathol. (2001) 158:867-77. doi: 10.1016/S0002-9440(10)64035-7

120. Lee KM, Danuser R, Stein JV, Graham D, Nibbs RJ, Graham GJ. The chemokine receptors ACKR2 and CCR2 reciprocally regulate lymphatic vessel density. EMBO J. (2014) 33:2564-80. doi: 10.15252/embj.2014 88887

121. Nibbs RJ, Gilchrist DS, King V, Ferra A, Forrow S, Hunter KD, et al. The atypical chemokine receptor D6 suppresses the development of chemically induced skin tumors. J Clin Invest. (2007) 117:1884-92. doi: 10.1172/JCI30068

122. Vetrano S, Borroni EM, Sarukhan A, Savino B, Bonecchi R, Correale C, et al. The lymphatic system controls intestinal inflammation and inflammationassociated Colon Cancer through the chemokine decoy receptor D6. Gut. (2010) 59:197-206. doi: 10.1136/gut.2009.183772

123. Savino B, Caronni N, Anselmo A, Pasqualini F, Borroni EM, Basso G, et al. ERK-dependent downregulation of the atypical chemokine receptor D6 drives tumor aggressiveness in Kaposi sarcoma. Cancer Immunol Res. (2014) 2:679-89. doi: 10.1158/2326-6066.CIR-13-0202

124. Pacifico F, Lepore A, Mellone S, Sanguigno L, Federico G, Greco A, et al. The chemokine scavenging receptor D6/ACKR2 is a target of miR-146a in thyroid cancer. Genes Cancer. (2017) 8:577-88. doi: 10.18632/genesandcancer.141

125. Bodduluri SR, Mathis S, Maturu P, Krishnan E, Satpathy SR, Chilton PM, et al. Mast cell-dependent $\mathrm{CD}^{+}{ }^{+} \mathrm{T}$-cell recruitment mediates immune surveillance of intestinal tumors in Apc(Min/+) mice. Cancer Immunol Res. (2018) 6:332-47. doi: 10.1158/2326-6066.CIR-17-0424
126. Rajagopal S, Kim J, Ahn S, Craig S, Lam CM, Gerard NP, et al. Beta-arrestinbut not G protein-mediated signaling by the "decoy" receptor CXCR7. Proc Natl Acad Sci USA. (2010) 107:628-32. doi: 10.1073/pnas.0912852107

127. Scala S. Molecular pathways, targeting the CXCR4-CXCL12 axis-untapped potential in the tumor microenvironment. Clin Cancer Res. (2015) 21:427885. doi: 10.1158/1078-0432.CCR-14-0914

128. Freitas C, Desnoyer A, Meuris F, Bachelerie F, Balabanian K, Machelon $\mathrm{V}$. The relevance of the chemokine receptor ACKR3/CXCR7 on CXCL12mediated effects in cancers with a focus on virus-related cancers. Cytokine Growth Factor Rev. (2014) 25:307-16. doi: 10.1016/j.cytogfr.2014.04.006

129. Sun X, Cheng G, Hao M, Zheng J, Zhou X, Zhang J, et al. CXCL12/CXCR4 / CXCR7 chemokine axis and cancer progression. Cancer Metastasis Rev. (2010) 29:709-22. doi: 10.1007/s10555-010-9256-x

130. Ieranò C, Santagata S, Napolitano M, Guardia F, Grimaldi A, Antignani E, et al. CXCR4 and CXCR7 transduce through mTOR in human renal cancer cells. Cell Death Dis. (2014) 5:e1310. doi: 10.1038/cddis.2014.269

131. Wu YC, Tang SJ, Sun GH, Sun KH. CXCR7 mediates TGFbeta1-promoted EMT and tumor-initiating features in lung cancer. Oncogene. (2016) 35:2123-32. doi: 10.1038/onc.2015.274

132. Wang J, Shiozawa Y, Wang J, Wang Y, Jung Y, Pienta KJ, et al. The role of CXCR7/RDC1 as a chemokine receptor for CXCL12/SDF-1 in prostate cancer. J Biol Chem. (2008) 283:4283-94. doi: 10.1074/jbc.M707465200

133. Maishi N, Ohga N, Hida Y, Akiyama K, Kitayama K, Osawa T, et al. CXCR7, a novel tumor endothelial marker in renal cell carcinoma. Pathol Int. (2012) 62:309-17. doi: 10.1111/j.1440-1827.2012.02792.x

134. Comerford I, Nibbs RJ, Litchfield W, Bunting M, Harata-Lee Y, HaylockJacobs S, et al. The atypical chemokine receptor CCX-CKR scavenges homeostatic chemokines in circulation and tissues and suppresses Th17 responses. Blood. (2010) 116:4130-40. doi: 10.1182/blood-2010-01-264390

135. Shi JY, Yang LX, Wang ZC, Wang LY, Zhou J, Wang XY, et al. CC chemokine receptor-like 1 functions as a tumour suppressor by impairing CCR7related chemotaxis in hepatocellular carcinoma. J Pathol. (2015) 235:546-58. doi: $10.1002 /$ path. 4450

136. Feng LY, Ou ZL, Wu FY, Shen ZZ, Shao ZM. Involvement of a novel chemokine decoy receptor CCX-CKR in breast cancer growth, metastasis and patient survival. Clin Cancer Res. (2009) 15:2962-70. doi: 10.1158/1078-0432.CCR-08-2495

137. Zhu Y, Tang W, Liu Y, Wang G, Liang Z, Cui L. CCX-CKR expression in colorectal cancer and patient survival. Int J Biol Markers. (2014) 29:e40-8. doi: $10.5301 /$ jbm.5000057

138. Harata-Lee Y, Turvey ME, Brazzatti JA, Gregor CE, Brown MP, Smyth $\mathrm{MJ}$, et al. The atypical chemokine receptor CCX-CKR regulates metastasis of mammary carcinoma via an effect on EMT. Immunol Cell Biol. (2014) 92:815-24. doi: 10.1038/icb.2014.58

Conflict of Interest Statement: The authors declare that the research was conducted in the absence of any commercial or financial relationships that could be construed as a potential conflict of interest.

Copyright (c) 2019 Mollica Poeta, Massara, Capucetti and Bonecchi. This is an openaccess article distributed under the terms of the Creative Commons Attribution License (CC BY). The use, distribution or reproduction in other forums is permitted, provided the original author(s) and the copyright owner(s) are credited and that the original publication in this journal is cited, in accordance with accepted academic practice. No use, distribution or reproduction is permitted which does not comply with these terms. 